\title{
Parameter Prediction of Water Imbibition in Unsaturated Shales Using the NMR Method
}

\author{
Jun Yang $\mathbb{D},{ }^{1}$ Jingyi Leng $\mathbb{D},{ }^{2}$ Linke Qiao $\mathbb{D},{ }^{1}$ Linlin Wang $\mathbb{D},{ }^{2}$ and Jiadi Ding $\mathbb{D}^{2}$ \\ ${ }^{1}$ State Key Laboratory for Geomechanics and Deep Underground Engineering, China University of Mining and Technology (Beijing), \\ Beijing 100083, China \\ ${ }^{2}$ College of Safety and Ocean Engineering, China University of Petroleum (Beijing), Beijing 102249, China
}

Correspondence should be addressed to Linlin Wang; linlin.wang@cup.edu.cn

Received 5 September 2019; Revised 28 October 2019; Accepted 5 November 2019; Published 21 December 2019

Academic Editor: Reza Rezaee

Copyright ( 2019 Jun Yang et al. This is an open access article distributed under the Creative Commons Attribution License, which permits unrestricted use, distribution, and reproduction in any medium, provided the original work is properly cited.

\begin{abstract}
Although the hydraulic fracturing treatment can improve the conductivity of shale reservoirs, the low recovery rate of the fracturing fluid may cause potential environmental and production issues. For an accurate investigation of these issues, an appropriate model of the water imbibition in shales is required. However, the hydraulic parameters related to water imbibition in shales are hard to be measured due to their tiny pores. In this study, an effective method is proposed to estimate the water imbibition volume. The nuclear magnetic resonance method is applied to obtain the related parameters including the capillary curve, the intrinsic and relative permeability of the shale, which can significantly cut down the time and cost needed to get these data. This model is validated by water imbibition experiments. In addition, we compare two empirical equations used to calculate intrinsic permeability in the NMR method and calibrate the corresponding parameter $a$ for shale, which is poorly investigated in literature. Finally, we suggest that the capillary force dominates the early stage of water imbibition process in unsaturated shales, and the late period may be influenced more by other mechanisms such as the osmosis and the surface hydration.
\end{abstract}

\section{Introduction}

Nowadays, due to the low permeability of the shale gas and oil reservoirs, horizontal wells stimulated by hydraulic fracturing are widely used to enhance the conductivity of the formation in the near-wellbore region. During the hydraulic fracturing process, a large amount of fracturing fluid will be injected into the formation, typically $1-1.4 \times 10^{5} \mathrm{bbls}$ $\left(5.75-7.75 \times 10^{5} \mathrm{ft}^{3}\right)[1,2]$. However, the recovery rate of this large volume of hydraulic fluid is very low (typically $30 \pm 10 \%$ ), which means that most of the fluid is left in the formation [1]. The residual fracturing fluid may cause both environmental and production issues. Whether this large volume of fluid will contaminate the underground drinking water [3], will the imbibed water lead to the instability of wells and fractures [4], will the fluid increase the gas and oil production at the early production period $[5,6]$, or will it damage the gas productivity in a long term $[7,8]$; all of these potential problems have become hot topics in recent years.
To figure out these issues, an exact description is essential for the water imbibition process involved in shales. Different from other geomaterials, shales are water-sensitive so that the water imbibition in them is unique and is governed by several mechanisms. Generally, three driving forces are commonly admitted, including the surface hydration, the osmosis, and the capillary force [9-12]. The capillary force is an important water imbibition force in all types of unsaturated rocks. And another two drive mechanisms only work in clay-bearing formations. The extremely narrow sheet-like structure of the clay minerals leads to strong intermolecular forces, causing adsorption of water molecules between the clay layers (i.e., micropores). This is called surface hydration. In addition, the isomorphic substitution phenomenon in clay particles (an assembly of clay layers with subparallel orientations) makes their surfaces negatively charged. These negatively charged surfaces give rise to a semipermeable membrane (osmosis) effect, enabling water to be sucked into interparticle spaces (i.e., mesopores) $[13,14]$. 
Among the three mentioned mechanisms, the capillary force occupies a dominant position in the water imbibition in shale gas reservoirs, because shale gas reservoirs typically have an initial water saturation less than $45 \%$ [15]. In order to describe the water imbibition process caused by the capillary force, several models have been proposed. The most accurate one should be the multiphase flow model, which considers both the gas and liquid transport [16]. However, although little assumption made makes the model more accurate, it also leads to a complicated computation process. So several simplified methods have been proposed based on different assumptions. For example, a piston-like displacement model is established, which assumes that the water imbibition process is in a piston-like manner, i.e., pores of different sizes saturated at the same time and only residual gas is left behind the water displacing front [17]. Another simplified method proposed by Richard neglects the effect of the gas phase transport and assumes a diffusion-type front. Its main difference from the piston-like model is that based on its assumption, water prefers to enter the small pores first and then the large ones [18].

No matter which method is employed to describe the water imbibition process, some information such as the capillary curve, the relative permeability and the intrinsic permeability of shales is needed. However, due to the low permeability of shales, these parameters are usually hard to be measured. For example, Wan et al. [19] conducted a series of saturating experiments under different humidity to obtain the capillary curve of a Cox shale. This method is accurate, but it takes about five months to get just one point on the curve. Besides, due to the extremely low permeability and the potential water sensitivity, the intrinsic permeability cannot be measured by water displacement like in other types of rocks [20]. Thus, gas is commonly used to measure the permeability of shales. However, it has been demonstrated that the permeability measured by gas is different from the true permeability in water displacement [21].

The permeability and the capillary curve are all related to the pore size distribution which can be determined by the nuclear magnetic resonance (NMR) method. The NMR method reflects the pore structure by detecting hydrogen atoms contained in water and hydrocarbon in tiny pores [22]. Various methods have been proposed to calculate the permeability by NMR measurement. These methods are attractive because permeability measurement by NMR can be done not only in cores but also directly in formations. It is more applicable, effective, and nondestructive compared with some conventional methods such as mercury intrusion porosimetry (MICP) and core displacement experiments, especially in some low-permeable rocks [23-29]. In addition, the capillary curve can also be obtained by the pore size distribution curve measured by NMR, whose quantified description can be obtained by an empirical formula proposed by Van Genutchen. What is more, the relation between the relative permeability and the saturation can also be obtained by Van Genutchen's model [30].

In this study, the water imbibition in shales is investigated theoretically and experimentally. Five parts are included in this paper. After the introduction, a complete model is proposed to describe the water imbibition process. The related parameters including the intrinsic permeability and the capillary curve are determined from the pore size distribution measured by NMR. Then, water imbibition experiments in shales are performed and monitored by the NMR method. Instead of conducting a series of time-consuming experiments and complicated permeability measurements, the NMR method can determine the intrinsic permeability and the capillary curve simply and efficiently. In the fourth part, the experimental results are employed to calibrate and validate the proposed model, and further discussions are provided. The final part is the conclusion.

\section{Theoretical Model}

2.1. Richard Equation. In Introduction, it has already been mentioned that three admitted mechanisms are responsible for the water uptake in shales. However, because of the low initial water saturation (less than $45 \%$ in reservoirs), the water imbibition process is dominated by the capillary pressure [9]. Hence, the osmotic effect and the surface hydration are neglected in this study.

The water imbibition in shales involves the transport of both the gas and liquid phases. The continuity equation for two-phase flow can be written as follows [16]:

$$
\frac{\partial\left(\phi S_{w}\right)}{\partial t}=-d i v q_{w}
$$

where $S_{w}$ is the wetting phase saturation (-); $\phi$ is the porosity $(-) ; t$ is the time $(s) ; q_{w}$ is the volumetric flux of the wetting phase $\left(\mathrm{m}^{3} / \mathrm{s}\right)$. The Darcy's law applied for wetting and nonwetting phase can be written as follows:

$$
\begin{gathered}
q_{w}=-\frac{k k_{r w}}{\mu_{w}} \nabla P_{w}, \\
q_{n w}=-\frac{k k_{r n w}}{\mu_{n w}} \nabla P_{n w},
\end{gathered}
$$

where $q_{n w}$ is the volumetric flux of the nonwetting phase $\left(\mathrm{m}^{3} / \mathrm{s}\right) ; k$ is the intrinsic permeability of the shale sample $\left(\mathrm{m}^{2}\right) ; k_{r n w}$ and $k_{r w}$ are the relative permeability of the nonwetting and wetting phase (-); $\mu_{n w}$ and $\mu_{w}$ are the viscosity of the nonwetting and wetting phase $(\mathrm{Pa} \cdot \mathrm{s}) ; P_{n w}$ and $P_{w}$ are the pressure of the nonwetting and wetting phase $(\mathrm{Pa})$. Note that the wetting phase in this study is water. The relation among the capillary force and the pressure of the two phases is given by

$$
P_{c}=P_{n w}-P_{w}
$$

where $P_{c}$ is the capillary force $(\mathrm{Pa})$. It has been demonstrated that the water-gas flow in low-permeable material is dominated by the water transport [16]. Hence, the transport of the gas phase is negligible, that is, $P_{c}=-P_{w}$. Applying this assumption in Equations (1), (2), and (3), Richard's model 
can be obtained, which can significantly simplify the computation. 1-D Richard's model is written as follows:

$$
\frac{\partial\left(\phi S_{w}\right)}{\partial t}=\frac{\partial}{\partial x}\left(-\frac{k k_{r w}}{\mu_{w}} \frac{\partial P_{c}}{\partial x}\right)
$$

where $x$ is the position (m). A 1-D model is employed in this study because the scale of water imbibition $(\mathrm{mm}-\mathrm{cm})$ is small [31] compared with the fracture length $(\mathrm{m})[2,32]$.

According to Equation (5), several parameters are needed to describe the water imbibition volume in unsaturated shales by Richard's model: the porosity of the shale, the initial water saturation, the intrinsic permeability, and the relative water permeability. In this study, the NMR method is used to obtain these data.

2.2. Intrinsic Permeability. The NMR measurement can detect the hydrogen atom. By monitoring the decay of the signal, a $T_{2}$ distribution can be obtained. $T_{2}$ is the transverse relaxation time, which is a set of attenuation coefficients correlating with the pore size. The larger the pore, the higher the $T_{2}$ value and vice versa. Thus, a pore size distribution curve can be calculated based on the $T_{2}$ distribution curve. The $x$-axis of the curve is $T_{2}$ value, which represents the pore size; the $y$-axis indicts the Amp value which reflects the volume fraction occupied by the corresponding size of pores. The $T_{2}$ distribution can be converted into the pore size distribution according to the following equation [33]:

$$
\frac{1}{T_{2}}=\rho\left(\frac{S}{V}\right)_{\text {pore }}
$$

where $\rho$ is the surface relaxivity $(\mathrm{m} / \mathrm{s}) ; S$ is the surface area of the pore $\left(\mathrm{m}^{2}\right) ; V$ is the pore volume $\left(\mathrm{m}^{3}\right)$. The specific area $(S / V)$ equals to $3 / r$ if the pore is assumed to be spherical and equals to $2 / r$ if a cylindrical model is applied, where $r$ is the radius of the pore $(\mathrm{m})$.

Based on the dependence of the permeability on the porosity and the pore size distribution, Seevers proposed an empirical equation which can calculate the intrinsic water permeability based on the NMR measurement [24, 26-29].

$$
k=a T_{2, \mathrm{LM}}^{2} \phi
$$

where $a$ is a parameter $\left(\mathrm{mD} /(\mathrm{ms})^{2}\right)$ depending on the surface relaxivity of the porous media; $T_{2, \mathrm{LM}}$ is the logarithmic mean of $T_{2}$ (ms), which can be calculated by

$$
T_{2, \mathrm{LM}}=10\left[\left(\sum_{i=1}^{N} V_{i} \log \left(T_{2 i} / 1 \mathrm{~ms}\right)\right) /\left(\sum_{i=1}^{N} V_{i}\right)\right],
$$

where $V_{i}$ is the volume fraction of pore $i(-)$.

The assessment of intrinsic permeability is very meaningful for low-permeable materials such as shales whose intrinsic permeability are complicated to be measured.

2.3. Capillary Curve. During the water imbibition process in unsaturated shale, the relative permeability changes with
TABLE 1: The XRD result of the shale sample.

\begin{tabular}{ccccccc}
\hline Mineral & Quartz & Plagioclase & Calcite & Dolomite & Pyrite & Illite \\
\hline Content & $43 \%$ & $1 \%$ & $22 \%$ & $27 \%$ & $1 \%$ & $6 \%$ \\
\hline
\end{tabular}

water saturation because of the two-phase flow. The variation of relative permeability with the water saturation is given by Van Genutchen [30, 34, 35]:

$$
k_{r w}=\sqrt{S_{e}}\left(1-\left[1-S_{e}^{1 / \mathrm{m}}\right]^{m}\right)^{2}, \text { with } S_{e}=\frac{S_{w}-S_{w r}}{S_{w s}-S_{w r}}
$$

where $S_{e}$ is the effective water saturation (-); $m$ is a Van Genutchten parameter; $S_{w r}$ is the residual water saturation $(-) ; S_{w s}$ is the water saturation when the shale is saturated. The relation between the water saturation and the capillary force given by Van Genuchten is expressed by [30]:

$$
S_{e}=\left[\frac{1}{1+\left(\alpha P_{c}\right)^{n}}\right]^{m}
$$

where $m=1-1 / n ; \alpha\left(\mathrm{Pa}^{-1}\right)$ is the second Van Genuchten parameter. From the microscopic scale, the capillary force can be obtained by the Young-Laplace equation:

$$
P_{c}=\frac{2 \sigma \cos \theta}{r},
$$

where $\sigma$ is the surface tension (Pa.m); $\theta$ is the contact angle (-). According to Equation (11), when capillary force reaches a given value, the pores smaller than the corresponding radius are all saturated. Thus, the saturation under given capillary force can be calculated by summing up the Amp values of the smaller pores, and then the capillary curve can be obtained from the pore size distribution curve measured by NMR. To make it clearer, an example is shown in the first part of the appendix. Compared to the conventional methods, our method is time-saving and can give a reliable result.

By far, an effective method is proposed to calculate the water imbibition in shales. The related parameters including the capillary curve and the intrinsic permeability can be obtained by the NMR method.

\section{Experiment}

3.1. Experiment Procedure. Two shale samples are drilled from an outcrop in Sichuan Basin, China. These two samples are numbered by $\mathrm{A}$ and $\mathrm{B}$. The lengths of these two cylindrical samples are $18.94 \mathrm{~mm}$ and $19.81 \mathrm{~mm}$, and their diameters are $24.96 \mathrm{~mm}$ and $24.85 \mathrm{~mm}$, respectively. The side faces of the samples are coated with epoxy resin, only the two ends exposed to the air, which involves a 1-D water imbibition process. The XRD data is shown in Table 1. It is worth noting that the clay content is low, and only illite exists. In illite, the negative charge caused by isomorphic substitution is mainly compensated by $\mathrm{K}^{+}$. Due to the suitable size of $\mathrm{K}^{+}$, it can be interlocked in the hexagonal cavity, which makes 


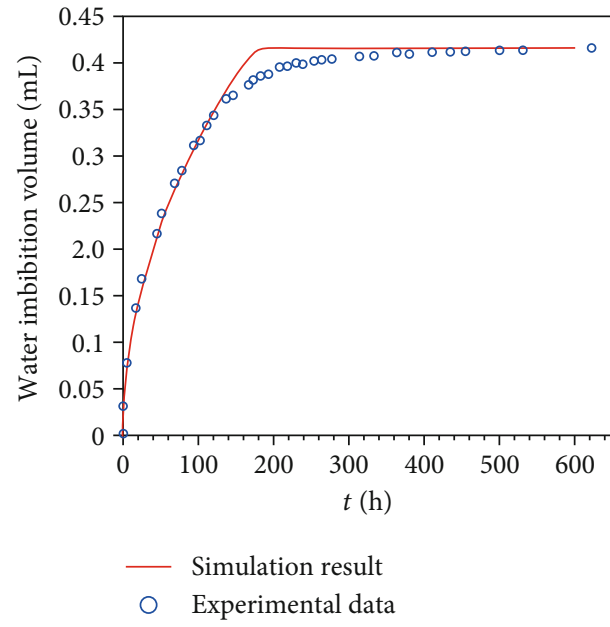

(a)

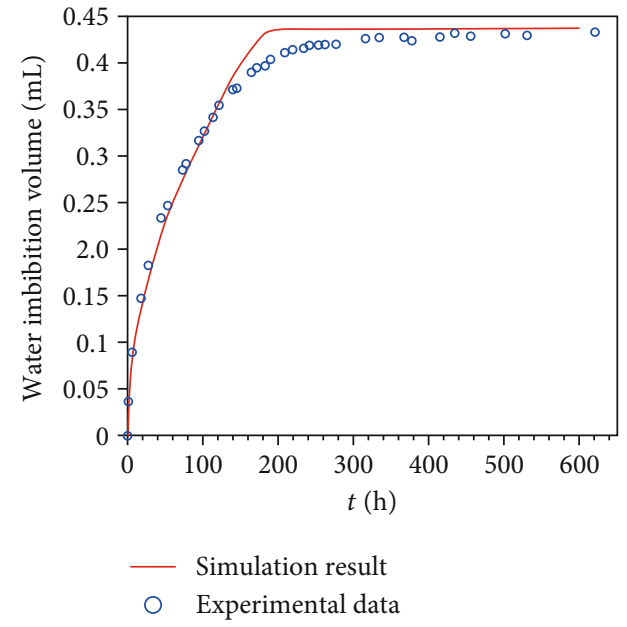

(b)

Figure 1: The variation of water imbibition volume with time. (a) Sample A. (b) Sample B (the weight is converted to volume by $\left.\rho_{w}=1.0 \mathrm{~g} / \mathrm{cm}^{3}\right)$.

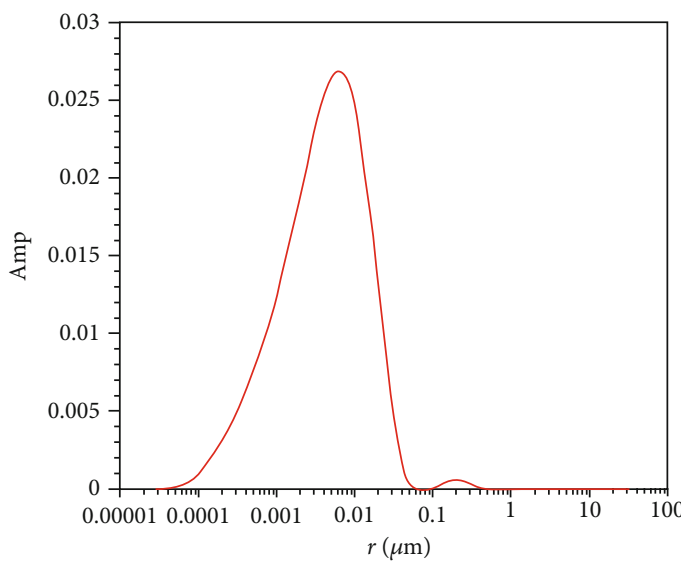

(a)

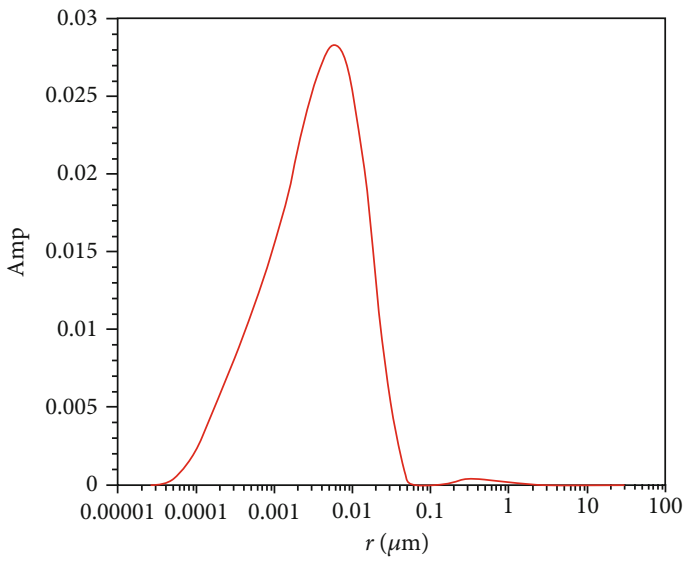

(b)

Figure 2: Pore size distribution. (a) Sample A. (b) Sample B.

the structure of illite stable [36, 37]. Hence, the interlayer spaces contribute little to the water imbibition.

Before the experiment, the samples are dried at $105^{\circ} \mathrm{C}$ for $72 \mathrm{~h}$ until the weight of the samples holds constant. The weights of the dry samples are recorded, and then NMR measurement is done to obtain their $T_{2}$ distributions. After that, the samples are put in deionized water. The variation of $T_{2}$ distribution and the weight change along with time are recorded during the whole process. The weights of the samples are measured by the balance after taking them out from water and wiping them. The accuracy of the balance is $0.001 \mathrm{~g}$. The NMR measurement is done every time after weighing the samples. The water imbibition experiment lasts for $621 \mathrm{~h}$ until the weights of both samples remain constant.

\subsection{Experiment Results}

3.2.1. Water Imbibition Curve. The weight changes of the samples measured by the balance are shown in Figure 1 . The water imbibition curves for both samples increase fast at the early water imbibition period. Then, the water imbibition rates decrease and eventually equal to zero until the end of the water imbibition.

3.2.2. NMR Measurement Result. The NMR method is employed to investigate the parameters related to the water imbibition process. Firstly, the $T_{2}$ distribution at the end of the experiment is converted into the pore size distribution using Equation (6). The surface relaxivity used here is $1.5 \mu \mathrm{m} / \mathrm{s}[38,39]$. The pores are assumed to be cylindrical, i.e., the specific area equals to $2 / r$. The curves obtained are shown in Figure 2. From the curves, it can be found that the pore size ranges from $0.02 \mathrm{~nm}$ to $0.3 \mu \mathrm{m}$. Both samples exhibit a peak at $6 \mathrm{~nm}$.

The intrinsic permeability is determined by two methods. Firstly, $T_{2, \mathrm{LM}}$ is calculated based on the Amp value of all the pores, finding that $T_{2, \mathrm{LM}}=1.22$ for sample A and 1.04 for sample B. However, micropores $(<2 \mathrm{~nm})$ in shales broadly correspond to be interlayer spaces, which are considered to 


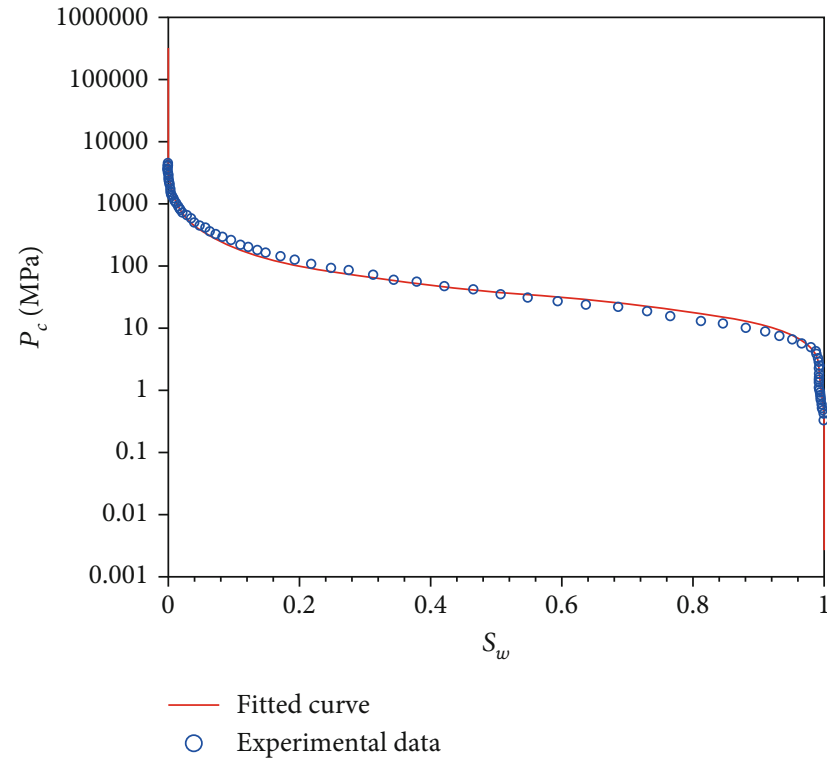

(a)

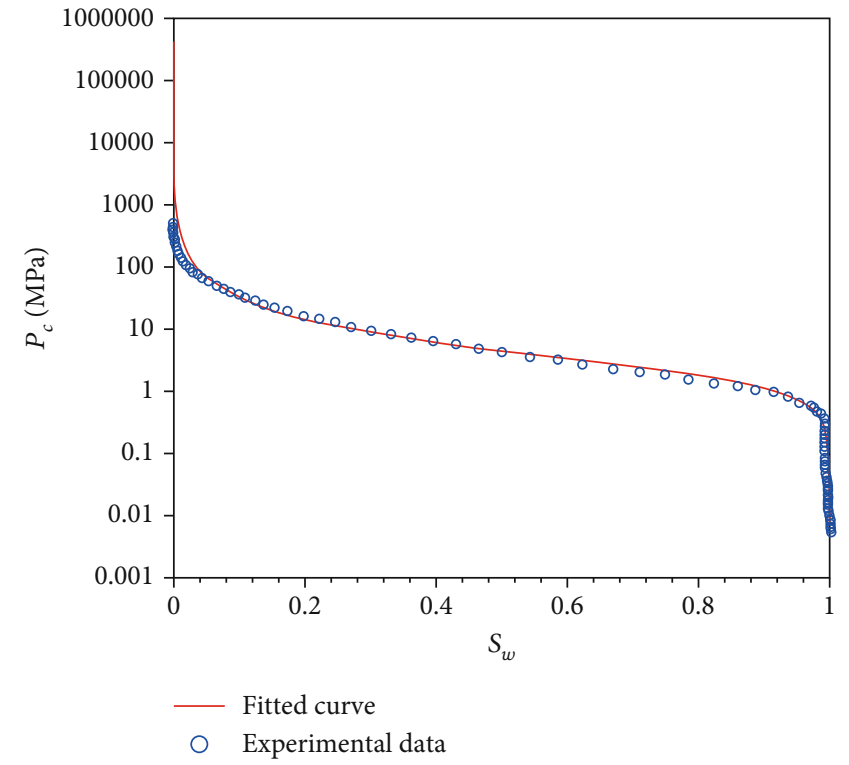

(b)

Figure 3: Fitting the capillary curve by Van Genutchen model ((a) is for sample A and (b) is for sample B).

TABLE 2: Parameters calculated by NMR measurement.

\begin{tabular}{cccccccc}
\hline & $m$ & $n$ & $\alpha$ & $\phi$ & $k$ & $S_{w i}$ \\
\hline A & 0.52 & 2.08 & $4.2 \times 10^{-8} \mathrm{~Pa}^{-1}$ & 0.0587 & $2.2 \times 10^{-22} \mathrm{~m}^{2}$ & 0.24 & 0 \\
B & 0.47 & 1.89 & $4.2 \times 10^{-8} \mathrm{~Pa}^{-1}$ & 0.0613 & $2.3 \times 10^{-22} \mathrm{~m}^{2}\left(a=1.99 \times 10^{-5} \mathrm{mD} /(\mathrm{ms})^{2}\right)$ & 0.27 & 0 \\
\hline
\end{tabular}

have little contributions to the water imbibition in this study due to the poor clay content and the stable structure of illite [14]. Accordingly, in the second method, $T_{2, \mathrm{LM}}$ is calculated based on Amp data of meso- and macropores, exclusive of micropores. The result of this method shows that $T_{2, \mathrm{LM}}$ values of both samples equal to 2.29. It should be noted that the $T_{2, \mathrm{LM}}$ for sample $\mathrm{A}$ is $17.5 \%$ higher than that for sample $\mathrm{B}$ in the first method, but the balance time of the two samples is very close to each other as shown in Figure 1. Thus, the second method is applied in the following. What is more, it is worth noting that only one peak occurs in the pore size distribution curve for both samples, which indicts that no microfractures involved in the shale samples.

To obtain the capillary curve, the capillary force at any given radius is firstly calculated according to the YoungLaplace equation (Equation (11)). The surface tension used here is $0.072 \mathrm{~Pa} \cdot \mathrm{m}$, and $\theta$ is assumed to be 0 in this study due to the relatively high quartz content $[40,41]$. Then, the corresponding water saturation can be calculated by the method mentioned in Section 2.3. After the calculation of accumulative Amp value mentioned in Section 2.3, it can be converted into the water weight based on a calibration experiment which shows that the Amp value for $10 \mathrm{~g}$ water is $10.6 \mu \mathrm{V}$. Note that the pore volume is calculated by adding up all the Amp values measured at the last time. Finally, by fitting the experimental data with Equation (10), the Van Genutchen parameters $(m, \alpha)$ can be calibrated from the capillary curve (see Figure 3); the values are shown in Table 2.

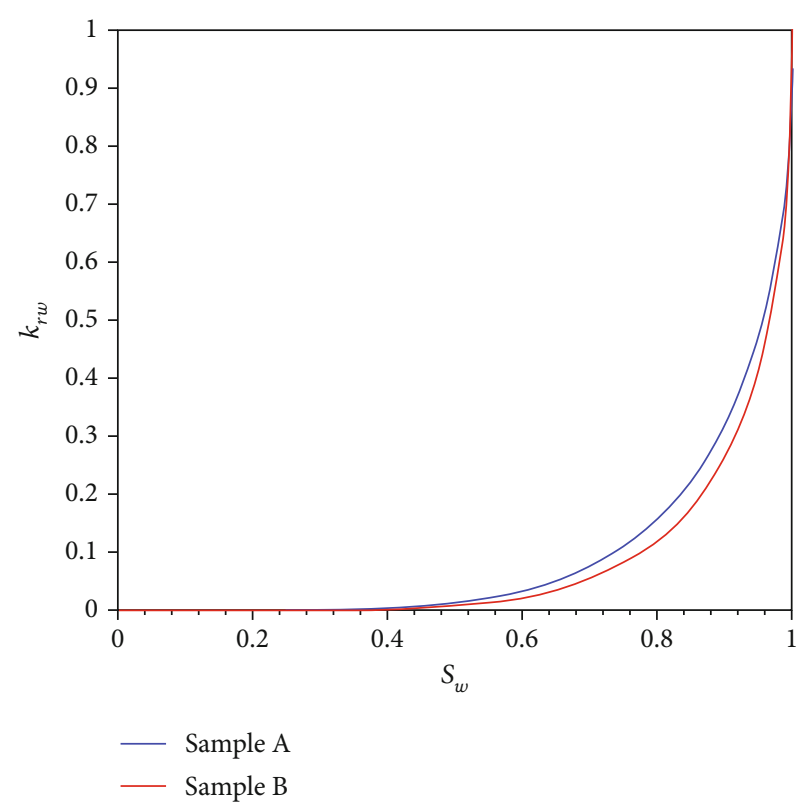

FIGURE 4: The variation of relative permeability with saturation.

It is worth noting that the smallest capillary force approximates to zero; thus, we assume that there is no residual gas in the sample, i.e., $S_{w s}=1$. All the parameters got from the NMR measurement are shown in Table 2 . The relation between relative permeability and the water saturation can be calculated by Equation (9) (see Figure 4). From Figure 4, it can be found 
that the relative permeability is almost zero until the water saturation reaches 0.4 .

\section{Simulation Results and Discussion}

Equation (5) is implemented into the software COMSOL to simulate the water imbibition process. A 1-D model is established. Because both ends of the samples are exposed to the water, the flow should be symmetrical. Thus, at the middle point of the sample, a no-flow boundary is applied, i.e., $q_{w}(l, t)=0$. Note that the $l$ here equals to the half-length of the sample $(9.470 \mathrm{~mm}$ for sample A and $9.905 \mathrm{~mm}$ for sample B). At the water inlet, the water saturation keeps to be 1 , and $P_{c}(0, t)=0$. The initial water saturation is 0.24 for sample A and 0.27 for sample B. It equals to the Amp value of the dry sample divided by that of the saturated one, that is, only the pores into which water can enter are considered when calculating the saturation. At the end of the simulation, the water imbibition volume is doubled and multiplied by the cross-sectional area of the sample to obtain the total water imbibition volume.

4.1. Validation of the Proposed Model. The exact value of $a$ for shales in Equation (7) is not available in the literature. Hence, this value is calibrated first by fitting the water imbibition curve of sample A, $k_{A}=2.2 \times 10^{-22} \mathrm{~m}^{2}$, and so $a=7.28 \times$ $10^{-7} \mathrm{mD} /(\mathrm{ms})^{2}$. Using the same $a$ value, we obtain $k_{B}=$ $2.3 \times 10^{-22} \mathrm{~m}^{2}$ and predict the imbibition curve, as shown in Figure 1(b). It is illustrated that the prediction fits well with the experimental data, which validates our proposed model. Note that the simulation result does not fit well with the late water imbibition period. This problem will be discussed later in Section 4.4 .

The total water imbibition volume of samples A and B is $0.41 \mathrm{~mL}$ and $0.43 \mathrm{~mL}$, respectively. The plot shows that the simulation results based on the NMR measurement fit well with the data measured by the balance. This can validate the NMR method used in this study.

The water imbibition in sample A equilibrates after about $360 \mathrm{~h}$ and sample B at approximately $340 \mathrm{~h}$, i.e., sample $B$ imbibes water faster. Because low permeability should lead to long balance time, this result is consistent with the intrinsic permeability result. However, comparing the relative permeability of the two samples which is shown in Figure 4, the relative permeability of sample A is generally higher than sample B. Hence, it can be inferred that the intrinsic permeability plays a more important role in terms of the balance time.

4.2. Intrinsic Permeability. Equation (7) is used in this work for the assessment of intrinsic permeability. It should be noted that another empirical equation proposed by Kenyon is more widely used, in which the intrinsic permeability is proportional to $\phi^{4}$ rather than $\phi[25]$ :

$$
k=a^{\prime} T_{2, \mathrm{LM}}^{2} \phi^{4}
$$

However, if this equation is used instead of Equation (7) to calculate the permeability of sample $B$, the permeability

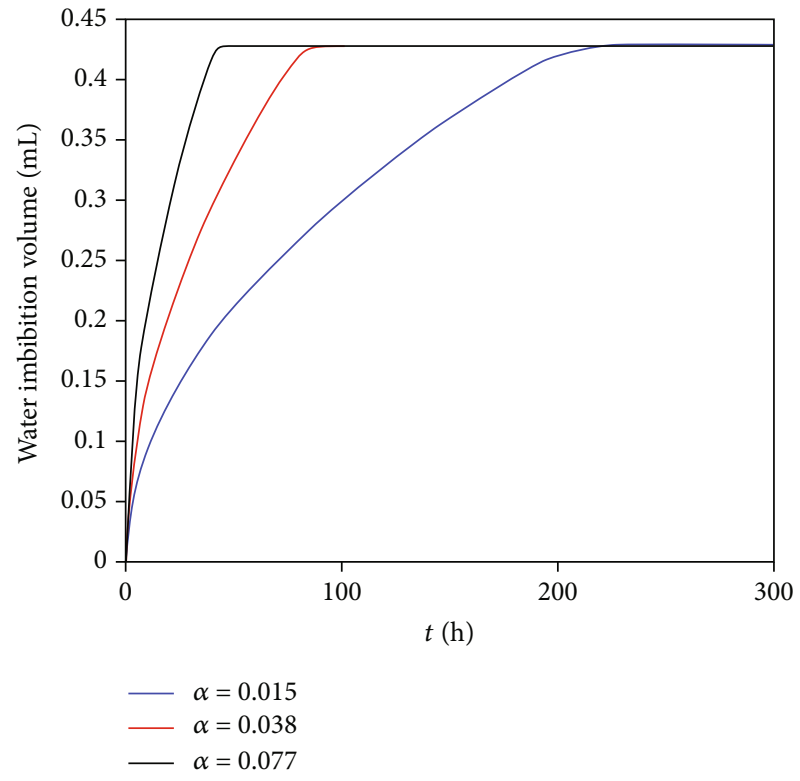

FIgURE 5: Water imbibition curves under various $a$ values.

equals to $2.63 \times 10^{-22} \mathrm{~m}^{2}$, which is $18.9 \%$ more than that of sample A. Compared with the permeability calculated by Equation (7) which is only $4.4 \%$ more, it is too large since the balance time of sample A is comparable with sample B. Thus, $\phi$ is preferred to describe the intrinsic permeability of shales in this study. However, according to the experiments conducted by Kenyon, $\phi^{4}$ fits better for sandstones [25]. This phenomenon suggests that the relation between the porosity and the permeability varies in different scenarios.

4.3. The Coefficient $a$. In this section, several different values of $a$ are taken to figure out $a$ 's effect on the water imbibition process, shown in Figure 5. A large $a$ decreases the balance time significantly but hardly affects the water imbibition volume.

A typical value for $a$ in sandstone is $4 \mathrm{mD} /(\mathrm{ms})^{2}$ [42], while $a=0.0036 \mathrm{mD} /(\mathrm{ms})^{2}$ for shales. Note that both values are based on Equation (12). From the comparison between the $a$ values in these two types of rocks, it can be inferred that, even if equal porosity is given, the intrinsic permeability may differ for different types of rocks. There are several potential reasons for this phenomenon: (1) the pores in shales are more tortuous, which may cause potential damage on the permeability when equal porosity is given; (2) clay minerals exist interpores in shales, which may damage the connectivity of the pores and cut down the effective pore volume; (3) the transport mechanism is also different when the pore size is extremely small. The adsorption of water molecules in the tiny pores occurs much slower than the water seepage in macropores.

4.4. Water Imbibition Simulation. The simulation result fits well at the beginning of the process, but it reaches equilibrium faster than the experiment. So, further investigation of this problem is done based on an analytical solution of the 


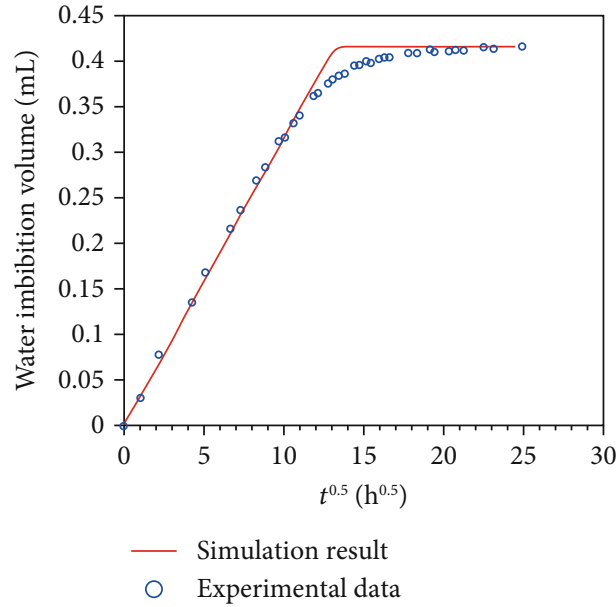

(a)

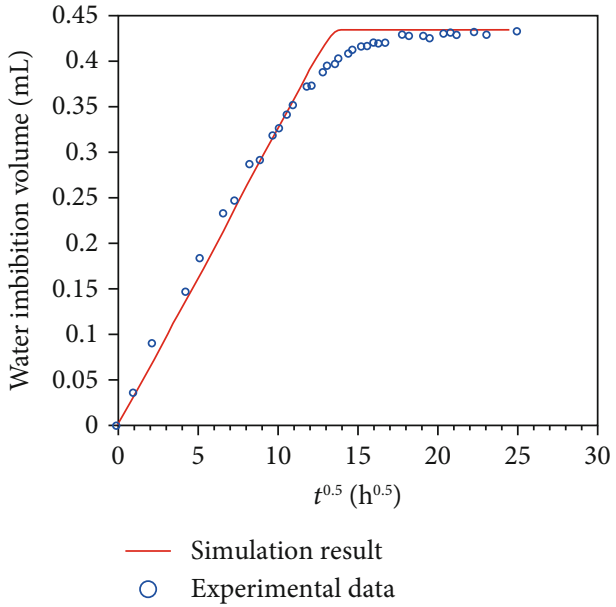

(b)

Figure 6: The variation of water imbibition volume with square root of time ((a) is for sample A and (b) is for sample B).

Richard's model. When applying Boltzmann transformation on Equation (5), there is a linear relation between the water imbibition volume and the square root of time whose derivation is shown in the second part of the appendix [43]:

$$
Q(t)=\int_{w_{d}}^{w_{s}} x d w=t^{1 / 2} \int_{w_{d}}^{w_{s}} \lambda(w) d w=S t^{1 / 2}
$$

where $Q(t)$ is the water imbibition volume of the sample (m); $w$ is the water content (-), the subscript $d$ and $s$ indicts dry and saturated, respectively; $S$ is the sorptivity $\left(\mathrm{m} / \mathrm{s}^{0.5}\right)$, which is a constant. The $x$-axis of the imbibition curve is changed to be the square root of $t$ to observe the variation of the slope. The plots are shown in Figure 6. It can be seen that the water imbibition confirms to Richard's model at the early period, which means that the capillary force dominates at the early stage. However, the final part separates from the linear relation. This variation of the slope might be related to the change of the water imbibition mechanism. The most possible reason is that the osmotic effect and the surface hydration also play a role in this process. The total water imbibition volume may include some water imbibition caused by these two mechanisms. Their contribution is relatively poor compared to that caused by the capillary force. Hence, they are nearly negligible when the capillary force induced water imbibition is strong at the beginning. However, after the macropores are saturated, more water begins to be absorbed into the micro- and mesopores by the osmotic effect or the surface hydration, and their contributions are more obvious due to the stop of water imbibition caused by capillary force. This is also consistent to the phenomenon observed in the experiment: although no significant deformation of the samples is observed at the end of the experiment, tiny broken pieces are found, which demonstrates that there may be some deformation caused by osmosis and surface hydration, but it is not significant. However, to figure out whether this is the true reason still needs further investigation.

\section{Conclusion}

This work investigates the water imbibition process in unsaturated shales theoretically and experimentally. The main findings are as follows:

The capillary curve and the permeability of shales are very hard or time-consuming to be measured by conventional methods. Our method by using NMR measurement can overcome these difficulties and gives a reliable prediction of the experimental data.

To assess the intrinsic permeability by the NMR data, two types of models are commonly used, in which the intrinsic permeability is proportional to the porosity $(\phi)$ or its forth order $\left(\phi^{4}\right)$. However, our results reveal that although $\phi^{4}$ works well in many other cases (mainly in sandstones), it performs poorly for shales. This means that the empirical equation itself needs local calibration when applied in different formations.

What is more, in our study, $a$ value, the empirical parameter involved when estimating the intrinsic permeability in the NMR method, is calculated for shales, which is poorly investigated in literature. This parameter of shales is much smaller than that of sandstones, which may be caused by the limited connectivity and tortuosity as well as the small pore size of shales.

Finally, we find that the experimental data fit well with Richard's model at the early water imbibition stage but separate in the late period, which may indict the existence of the osmotic effect and the surface hydration. However, it still needs further investigation.

\section{Appendix}

\section{A. Example on the Calculation of the Capillary Curve}

An example is presented in this section for readers to understand the calculation of capillary curve more clearly. 
The data obtained directly from the NMR measurement are the $T_{2}$ values and their corresponding Amp values, which can be converted to the pore diameter (according to Equation (6)) and the water content in given pore size (according to the calibration test mentioned in Section 3.2.2), respectively.

To obtain the capillary curve, the capillary force and corresponding water saturation are needed. The capillary force is calculated by Equation (11) based on the pore diameters. And the water saturation under different capillary force is calculated based on the data of the water content in pores with different sizes. In this study, since a diffusion front is assumed by applying the Richard's equation, the water saturation under given capillary force equals to the sum of water content in smaller pores divided by the water content in shales when the pores are saturated.

For example, $n$ groups of data are obtained by NMR measurement, which are sequenced according to the pore size from small to large. At group $i, T_{2}$ value $=T_{2}(i)$, Amp value $=\operatorname{Amp}(i)$, we can get

$$
\begin{aligned}
r_{i} & =2 \cdot T_{2}(i) \cdot \rho, \\
P_{c}(i) & =\frac{2 \sigma \cos \theta}{r_{i}}, \\
S_{w}(i) & =\frac{\left(\sum_{j=1}^{i} \operatorname{Amp}(i)\right)}{\left(\sum_{j=1}^{n} \operatorname{Amp}(i)\right)},
\end{aligned}
$$

where $P_{c}(i)$ and $S_{w}(i)$ are the capillary force and the water saturation corresponding to the $i^{\text {th }}$ group of data.

\section{B. Derivation of the Relation between $Q$ and $t^{1 / 2}$}

This section gives a brief derivation of Equation (13).

Equation (5) can be rearranged by replacing the $S_{w}$ by water content $w(-)$ :

$$
\frac{\partial w}{\partial t}=\frac{\partial}{\partial x}\left(D \frac{\partial w}{\partial x}\right)
$$

where $D$ is a diffusion coefficient $\left(\mathrm{m}^{2} / \mathrm{s}\right)$. To solve this partial differential equation, Boltzmann variable $\lambda=x t^{-1 / 2}$ is introduced to transform it into an ordinary differential equation:

$$
-\frac{\lambda}{2} \frac{d w}{d \lambda}=\frac{d}{d \lambda}\left(D \frac{d w}{d \lambda}\right)
$$

Further steps solving Equation (B.2) can be found in Mcwhorter's work [31] and will not be derived here. The solution of this equation gives a relation between $w$ and $\lambda$, i.e., $w$ is a function of $\lambda$ and vice versa. Rearrange the expression of Boltzmann variable:

$$
x(w, t)=\lambda(w) t^{1 / 2} .
$$

Hence, the water imbibition volume $(\mathrm{m})$ at $t$ can be calculated by Equation (13), which is proportional to the square root of $t$.

\section{Data Availability}

The experimental and simulation data used to support the findings of this study are included within the article.

\section{Conflicts of Interest}

The authors declare that there is no conflict of interest regarding the publication of this paper.

\section{Acknowledgments}

This work was supported by the National Natural Science Foundation of China (51809275).

\section{References}

[1] A. P. Byrnes, "Role of induced and natural imbibition in frac fluid transport and fate in gas shales," for the Hydraulic Fracturing Study: Fate and Transport, vol. 70, 2011.

[2] D. T. Birdsell, H. Rajaram, and G. Lackey, "Imbibition of hydraulic fracturing fluids into partially saturated shale," Water Resources Research, vol. 51, no. 8, pp. 6787-6796, 2015.

[3] M. T. Reagan, G. J. Moridis, N. D. Keen, and J. N. Johnson, "Numerical simulation of the environmental impact of hydraulic fracturing of tight/shale gas reservoirs on nearsurface groundwater: background, base cases, shallow reservoirs, short-term gas, and water transport," Water Resources Research, vol. 51, no. 4, pp. 2543-2573, 2015.

[4] M. E. Chenevert, "Shale alteration by water adsorption," Journal of Petroleum Technology, vol. 22, no. 9, pp. 1141-1148, 1970.

[5] A. Gupta, M. Xu, H. Dehghanpour, and D. Bearinger, "Experimental investigation for microscale stimulation of shales by water imbibition during the shut-in periods," in SPE Unconventional Resources Conference, Calgary, Alberta, Canada, 2017.

[6] O. A. Adefidipe, H. Dehghanpour, and C. J. Virues, "Immediate gas production from shale gas wells: a two-phase flowback model," in SPE Unconventional Resources Conference, The Woodlands, TX, USA, 2014.

[7] J. R. Shaoul, L. F. Van Zelm, and C. J. De Pater, "Damage mechanisms in unconventional-gas-well stimulation-a new look at an old problem," SPE Production \& Operations, vol. 26, no. 4, pp. 388-400, 2011.

[8] H. Scott, I. T. M. Patey, and M. T. Byrne, "Return permeability measurements - proceed with caution," in European Formation Damage Conference, Scheveningen, The Netherlands, 2007.

[9] H. Roshan, M. S. Andersen, H. Rutlidge, C. E. Marjo, and R. I. Acworth, "Investigation of the kinetics of water uptake into partially saturated shales," Water Resources Research, vol. 52, no. 4, pp. 2420-2438, 2016.

[10] L. Wang, M. Bornert, E. Héripré, S. Chanchole, A. Pouya, and B. Halphen, "Microscale insight into the influence of humidity on the mechanical behavior of mudstones," Journal of Geophysical Research: Solid Earth, vol. 120, no. 5, pp. 3173-3186, 2015.

[11] M. A. Q. Siddiqui, X. Chen, S. Iglauer, and H. Roshan, "A multiscale study on shale wettability: spontaneous imbibition vs contact angle," Water Resources Research, vol. 55, pp. 50125032,2019 . 
[12] H. Roshan, S. Ehsani, C. E. Marjo, M. S. Andersen, and R. I. Acworth, "Mechanisms of water adsorption into partially saturated fractured shales: an experimental study," Fuel, vol. 159, pp. 628-637, 2015.

[13] L. L. Wang, M. Bornert, E. Héripré, D. S. Yang, and S. Chanchole, "Irreversible deformation and damage in argillaceous rocks induced by wetting/drying," Journal of Applied Geophysics, vol. 107, pp. 108-118, 2014.

[14] L. L. Wang, M. Bornert, E. Héripré, S. Chanchole, A. Pouya, and B. Halphen, "The mechanisms of deformation and damage of mudstones: a micro-scale study combining ESEM and DIC," Rock Mechanics and Rock Engineering, vol. 48, no. 5, pp. 1913-1926, 2015.

[15] L. L. Wang, G. Q. Zhang, S. Hallais, A. Tanguy, and D. S. Yang, "Swelling of shales: a multiscale experimental investigation," Energy \& Fuels, vol. 31, no. 10, pp. 10442-10451, 2017.

[16] M. Mainguy, O. Coussy, and V. Baroghel-Bouny, "Role of air pressure in drying of weakly permeable materials," Journal of Engineering Mechanics, vol. 127, no. 6, pp. 582-592, 2001.

[17] L. L. Handy, "Determination of Effective Capillary Pressures for Porous Media from Imbibition Data," Society of Petroleum Engineers, vol. 219, pp. 75-80, 1960.

[18] L. A. Richards, "Capillary conduction of liquids through porous mediums," Physics, vol. 1, no. 5, pp. 318-333, 1931.

[19] M. Wan, P. Delage, A. M. Tang, and J. Talandier, "Water retention properties of the Callovo-Oxfordian claystone," International Journal of Rock Mechanics and Mining Sciences, vol. 64, no. 12, pp. 96-104, 2013.

[20] X. Cui, A. M. M. Bustin, and R. M. Bustin, "Measurements of gas permeability and diffusivity of tight reservoir rocks: different approaches and their applications," Geofluids, vol. 9, no. 3, 223 pages, 2009.

[21] D. L. Luffel, C. W. Hopkins, and P. D. Schettler Jr., "Matrix permeability measurement of gas productive shales," in SPE Annual Technical Conference and Exhibition, Houston, TX, USA, 1993.

[22] A. Al Hinai, R. Rezaee, L. Esteban, and M. Labani, "Comparisons of pore size distribution: a case from the Western Australian gas shale formations," Journal of Unconventional Oil and Gas Resources, vol. 8, pp. 1-13, 2014.

[23] H. Minagawa, Y. Nishikawa, I. Ikeda et al., "Characterization of sand sediment by pore size distribution and permeability using proton nuclear magnetic resonance measurement," Journal of Geophysical Research, vol. 113, no. B7, 2008.

[24] D. O. Seevers, "A nuclear magnetic method for determining the permeability of sandstones," in SPWLA 7th Annual Logging Symposium, Tulsa, OK, USA, 1966.

[25] W. E. Kenyon and J. A. Kolleeny, "NMR surface relaxivity of calcite with adsorbed $\mathrm{Mn}^{2+}$," Journal of Colloid and Interface Science, vol. 170, no. 2, pp. 502-514, 1995.

[26] O. Mohnke and U. Yaramanci, "Pore size distributions and hydraulic conductivities of rocks derived from magnetic resonance sounding relaxation data using multi-exponential decay time inversion," Journal of Applied Geophysics, vol. 66, no. 3-4, pp. 73-81, 2008.

[27] H. Pape, J. Arnold, R. Pechnig et al., "Permeability prediction for low porosity rocks by mobile NMR," Pure and Applied Geophysics, vol. 166, no. 5-7, pp. 1125-1163, 2009.

[28] D. Walsh, P. Turner, E. Grunewald et al., "A small-diameter NMR logging tool for groundwater investigations," Groundwater, vol. 51, no. 6, pp. 914-926, 2013.
[29] O. Mohnke, "Jointly deriving NMR surface relaxivity and pore size distributions by NMR relaxation experiments on partially desaturated rocks," Water Resources Research, vol. 50, no. 6, pp. 5309-5321, 2014.

[30] M. T. Van Genuchten, "A closed-form equation for predicting the hydraulic conductivity of unsaturated soils 1," Soil Science Society of America Journal, vol. 44, no. 5, pp. 892-898, 1980.

[31] T. Engelder, "Capillary tension and imbibition sequester frack fluid in Marcellus gas shale," Proceedings of the National Academy of Sciences of the United States of America, vol. 109, no. 52, pp. E3625-E3625, 2012.

[32] D. B. McWhorter and D. K. Sunada, "Exact integral solutions for two-phase flow," Water Resources Research, vol. 26, no. 3, pp. 399-413, 1990.

[33] M. H. Cohen and K. S. Mendelson, "Nuclear magnetic relaxation and the internal geometry of sedimentary rocks," Journal of Applied Physics, vol. 53, no. 2, pp. 1127-1135, 1982.

[34] M. K. Peters, A. Hemp, T. Appelhans et al., "Climate-land-use interactions shape tropical mountain biodiversity and ecosystem functions," Nature, vol. 568, no. 7750, pp. 88-92, 2019.

[35] J. M. Pflug, G. E. Liston, B. Nijssen, and J. D. Lundquist, “Testing model representations of snowpack liquid water percolation across multiple climates," Water Resources Research, vol. 55, no. 6, pp. 4820-4838, 2019.

[36] H. E. Gaudette, J. L. Eades, and R. E. Grim, "The nature of illite," Clays and Clay Minerals, vol. 13, no. 1, pp. 33-48, 1964.

[37] L. L. Wang, M. Bornert, S. Chanchole et al., "Micro-scale experimental investigation of the swelling anisotropy of the Callovo-Oxfordian argillaceous rock," Clay Minerals, vol. 48, no. 2, pp. 391-402, 2013.

[38] I. D. Sulucarnain, C. H. Sondergeld, and C. S. Rai, “An NMR study of shale wettability and effective surface relaxivity," in SPE Canadian Unconventional Resources Conference, Calgary, Alberta, Canada, 2012.

[39] R. Lewis, P. Singer, T. Jiang, E. Rylander, S. Sinclair, and R. H. Mclin, "NMR T2 distributions in the Eagle Ford Shale: reflections on pore size," in SPE Unconventional Resources Conference-USA, The Woodlands, TX, USA, 2013.

[40] M. A. Q. Siddiqui, S. Ali, H. Fei, and H. Roshan, "Current understanding of shale wettability: a review on contact angle measurements," Earth-Science Reviews, vol. 181, pp. 1-11, 2018.

[41] H. Roshan, A. Z. Al-Yaseri, M. Sarmadivaleh, and S. Iglauer, "On wettability of shale rocks," Journal of Colloid and Interface Science, vol. 475, pp. 104-111, 2016.

[42] C. E. Morriss, R. Freedman, C. Straley, M. Johnston, H. J. Vinegar, and P. N. Tutunjian, "Hydrocarbon saturation and viscosity estimation from NMR logging in the Belridge diatomite," in SPWLA 35th Annual Logging Symposium, vol. 38 of Society of Petrophysicists and Well-Log Analysts, p. 29, Tulsa, OK, USA, 1994.

[43] J. R. Philip, "The theory of infiltration," Soil Science, vol. 84, no. 3, pp. 257-264, 1957. 

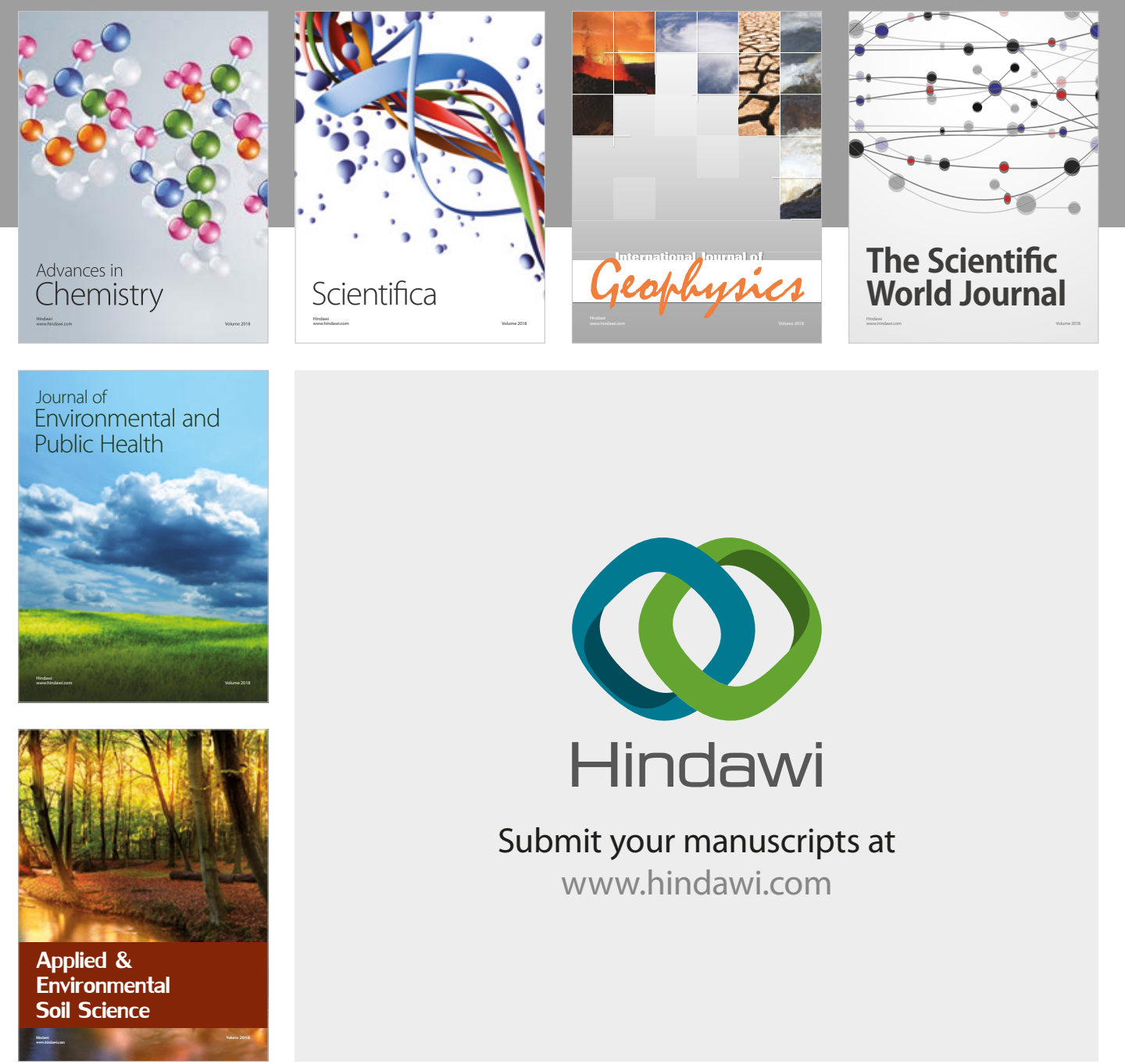

The Scientific

\section{World Journal}
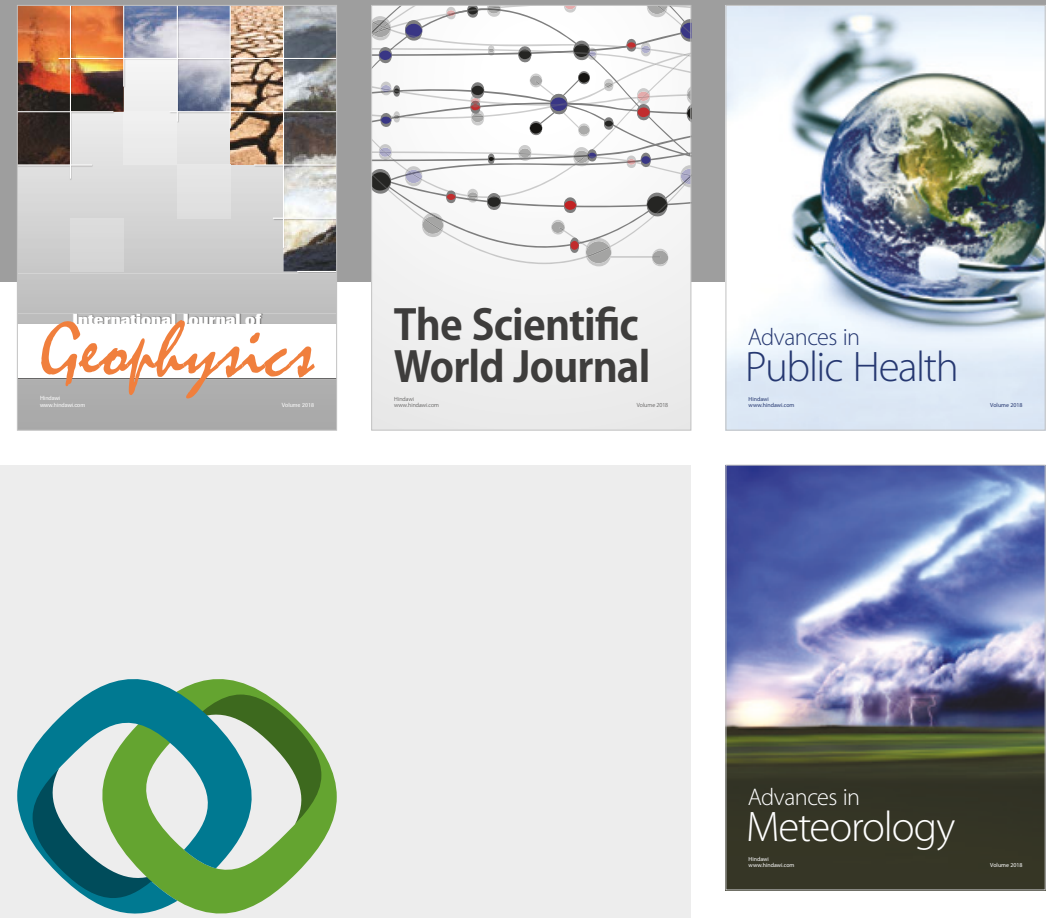

Advan

Public Health

\section{Hindawi}

Submit your manuscripts at

www.hindawi.com
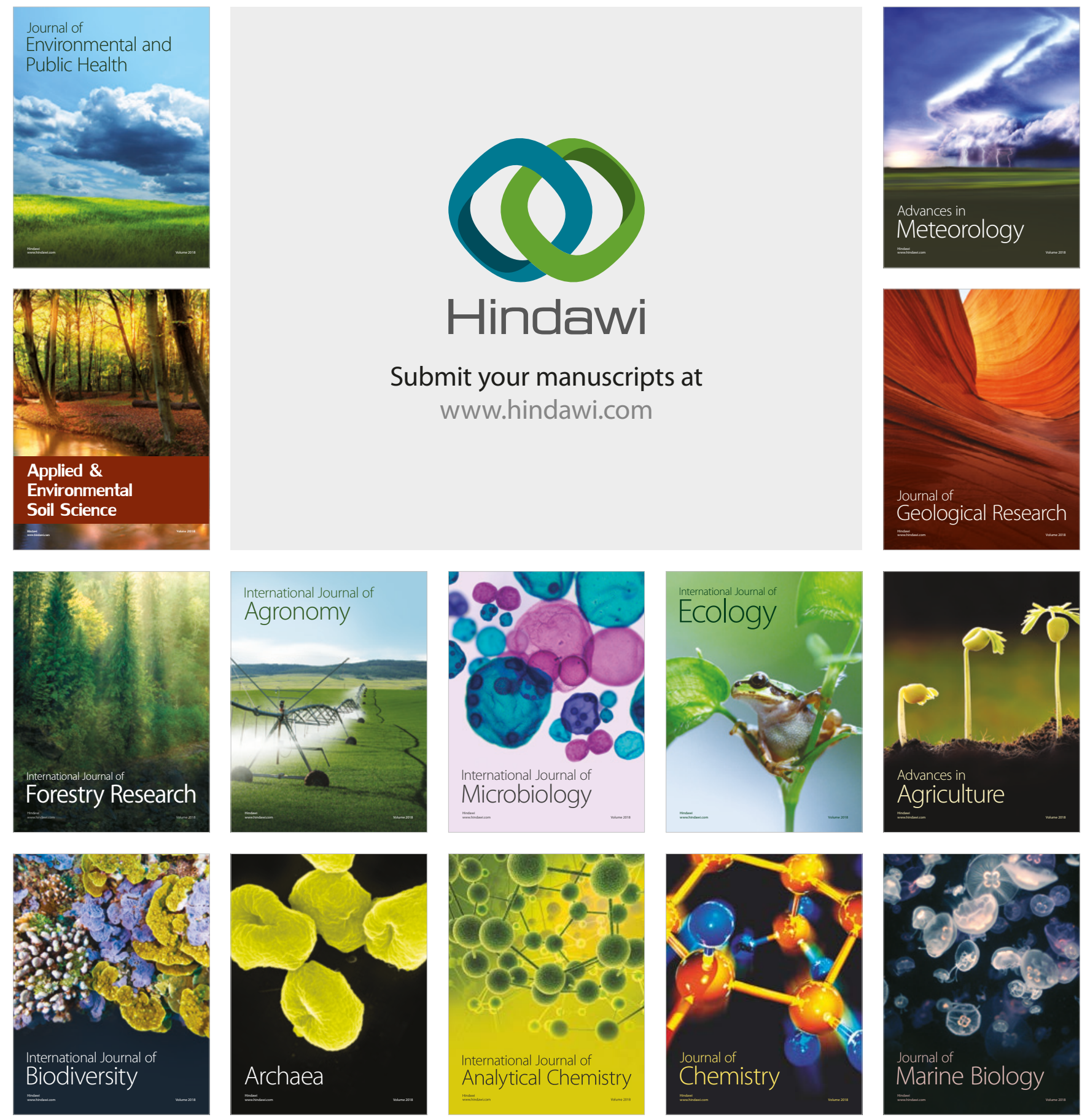